\title{
然 \\ A QUEM INTERESSAM AS POLÍTICAS AMBIENTAIS? REDES DE FINANCIAMENTO ELEITORAL EMPRESARIAL NA COMISSÃO DE MEIO AMBIENTE E DESENVOLVIMENTO SUSTENTÁVEL (CMADS) DA CÂMARA DOS DEPUTADOS

\author{
WHO IS INTERESTED IN ENVIRONMENTAL POLICIES? NETWORKS OF \\ CORPORATE ELECTORAL FINANCING IN THE COMMISSION FOR \\ ENVIRONMENT AND SUSTAINABLE DEVELOPMENT (CEDS) OF THE CHAMBER \\ OF DEPUTIES
}

\section{¿A QUIÉN INTERESAN LAS POLÍTICAS MEDIOAMBIENTALES? REDES DE FINANCIACIÓN ELECTORAL EMPRESARIAL EN LA COMISIÓN DE MEDIO AMBIENTE Y DESARROLLO SOSTENIBLE (CMADS) DE LA CÁMARA DE DIPUTADOS}

\author{
Rodrigo Rossi Horochovski* \\ Ivan Jairo Junckes** \\ Tainá Reis Serafim***
}

\begin{abstract}
Resumo: $\mathrm{O}$ artigo examina as redes de financiamento eleitoral empresarial dos deputados federais integrantes da Comissão de Meio Ambiente e Desenvolvimento Sustentável (CMADS), na 55a Legislatura (2015-2018). Duas questões guiaram o estudo: como é a estrutura da rede de financiamento dos membros da CMADS? Quais grupos de capital político-econômico se formam e se conectam dentro desta rede? Para respondê-las, coletamos dados de prestação de contas das eleições de 2014, do Repositório de Dados Eleitorais do Tribunal Superior Eleitoral (TSE), e dos relatórios da CMADS, disponíveis no portal da Câmara dos Deputados. Por meio da metodologia de Análise das Redes Sociais (ARS), encontramos uma estrutura de relações hierarquizada e coesa, com poucas empresas, com claros interesses na agenda ambiental, exercendo papel central na rede, por meio de doações de campanha.
\end{abstract}

Palavra-Chave: Financiamento Eleitoral; Análise de Redes Sociais (ARS); Câmara dos Deputados; $55^{\mathrm{a}}$ Legislatura; Comissão do Meio Ambiente e Desenvolvimento Sustentável (CMDAS).

Abstract: The article exams the companies' electoral finance networks of the federal deputies who
composed the Committee on Environment and Sustainable Development (CESD) in the 55th Legislature
(2011-2014). Two questions guided our study: how is the structure of the analyzed network? Which groups

*Professor do Curso de Administração Pública e dos Programas de Pós-Graduação em Ciência Política e em Desenvolvimento Territorial Sustentável, da Universidade Federal do Paraná. E-mail: rodrigoh33@gmail.com. ORCID iD: https://orcid.org/0000-0003-1135-0543.

** Professor do Curso de Administração Pública e do Programa de Pós-Graduação em Desenvolvimento Territorial Sustentável, da Universidade Federal do Paraná. E-mail: ivanjairojunckes@gmail.com. ORCID iD: https://orcid.org/0000-0001-8305-3754.

${ }^{* * * *}$ Gestora Pública e Mestranda em Desenvolvimento Territorial Sustentável, pela Universidade Federal do Paraná. Email: taina.reis13@gmail.com. ORCID iD: https://orcid.org/0000-0001-7996-4264. 
of political-economic capital are formed and connected into this network? To answer, we have collected data in the Superior Electoral Court (SEC) Electoral Data Repository as well as in the CESD reports available on the Chamber of Deputies website. Throughout Social Network Analysis (SNA), we found a hierarchic and cohesive structure with a few companies, having clear interests in the environmental agenda, playing central roles in the network by campaign donations.

Keywords: Electoral Finance; Social Network Analysis (SNA); The Chamber of Deputies; 55th Legislature; Committee on Environment and Sustainable Development (CESD).

Resumén: El artículo examina las redes de financiación electoral empresarial de los diputados federales que compusieron la Comisión de Medio Ambiente y Desarrollo Sostenible (CMADS), en la 54 $4^{\mathrm{a}}$ Legislatura (2011-2014). Dos preguntas orientan el estudio: ¿Cómo es la estructura de financiación de los miembros de la CMADS? ¿Qué grupos de capital político-económico se forman y se conectan dentro de esta red? Para responderlas, colectamos datos de rendición de cuentas de las elecciones de 2014, desde el Repositorio de Datos Eleitorales de la Tribunal Superior Eleitoral (TSE), y de los reportes de la CMADS, disponibles en el portal da Camara de los Diputados. A través de la metodología del Análisis de Redes Sociales (ARS), encontramos una estructura de relaciones jerarquizada y muy unida, con pocas empresas, con evidentes intereses en la agenda ambiental, ejerciendo un rol central en la rede, mediante donaciones de campaña.

Palabras clave: Financiación Electoral; Análisis de las Redes Sociales (ARS); Cámara de los Diputados; 55 Legislatura; Comisión de Medio Ambiente y Desarrollo Sostenible (CMADS).

\section{Introdução}

Em seu funcionamento no mundo real, as democracias enfrentam uma ambivalência, de difícil superação, na medida em que se colocam em choque duas classes de princípios que lhe são essenciais: a igualdade política e as liberdades de associação e expressão. A primeira prescreve que todos os sujeitos de uma politeia tenham iguais oportunidades, formais e substantivas, de tomar parte nas decisões que lhes afetam. Isso implica oportunidades de participar, direta ou indiretamente, da maneira mais livre e equitativa possível, de todas as etapas que constituem os processos decisórios, desde a construção dos problemas públicos e seu agendamento até a implementação das políticas públicas, passando pelos processos formais de decisão. A operacionalização deste princípio acarreta que os atores sociais participem de processos como a deliberação pública, a vida partidária, as eleições e decisões em si, entre outros ${ }^{1}$.

A liberdade de associação pressupõe que os atores sociais são livres para organizar-se em grupos para promover e/ou defender objetivos e interesses específicos, que incluem inúmeras possibilidades, como a constituição de famílias e outros grupos de sociabilidade, organizações de

\footnotetext{
${ }^{1}$ A literatura sobre o poder é uma das mais competentes na demonstração das dificuldades de implantação deste princípio (BACHRACH; BARATZ, 1962; LUKES, 1974; GAVENTA, 1982).
} 
trabalho, incluindo empresas, a ação político-partidária, religiosa, sindical, etc. Tal princípio ligase umbilicalmente à liberdade de expressão, pela qual os atores são livres para ter, defender e difundir ideias, crenças, concepções e ideologias. Presumivelmente, todos esses princípios são alinhados e complementares. Por que então se chocam?

Em contextos de profundas assimetrias na distribuição de recursos materiais e simbólicos, os atores sociais individuais e coletivos apresentam capacidades muito desiguais de exercer as liberdades de associação e expressão. Isso se coloca sensivelmente para o financiamento da política, mormente quando, por exemplo, indivíduos e empresas que concentram riquezas em um nível muito superior à média não encontram coerções significativas ao ato de doar, ou mais precisamente investir, recursos financeiros para partidos e candidatos. Em tal cenário, a igualdade política, elemento que originalmente constituiu a própria definição de democracia, pode ser seriamente constrangida (PRZEWORSKI, 2012).

Daniel Zovatto diz que a democracia não tem preço, mas tem custos. Em estudo comparado sobre países do subcontinente, este autor, ao mesmo tempo em que defende a necessidade de a política ser financiada, mostra que o dinheiro se tornou determinante nas campanhas eleitorais, de modo que o financiamento político se tornou uma verdadeira dor de cabeça (ZOVATTO, 2005). A questão não se circunscreve ao contexto latino-americano, de históricos déficits democráticos. Estudos como os de Bourdokan (2009), envolvendo 109 países, ou de Falguera, Jones e Ohman (2014), patrocinado pelo International IDEA (International Institute for Democracy and Electoral Assistance), descortinam a participação residual do cidadão comum nas receitas de campanhas eleitorais. Onde o financiamento privado prevalece, as doações empresariais representam quase a totalidade dos recursos transacionados. Como na maioria dos casos não há regras que imponham uma distribuição igualitária desses recursos, o resultado é que partidos e candidatos dramaticamente necessitam do apoio de grupos privados de capital para suas campanhas. Com o apoio, potencialmente se estabelece a pressão pela defesa de interesses específicos desses grupos durante o mandato.

Temos, portanto, um problema muito prático para o regime democrático, notadamente para a produção das políticas públicas que, ao fim e ao cabo, dirão para onde a ação do aparelho estatal - de permitir ou bloquear - e os recursos públicos serão direcionados. Não é diferente com a área ambiental. Desse modo, uma tarefa básica e inicial de quem pesquisa a produção de políticas públicas ambientais é identificar os interesses que se constituem em torno das agendas. É a isso que nos propomos, apresentando os principais achados de pesquisa sobre as redes de financiamento eleitoral dos deputados federais integrantes da Comissão de Meio Ambiente e Desenvolvimento Sustentável (CMADS), na 55ª Legislatura (2015-2018).

O objetivo principal é identificar os grupos centrais de capital político-econômico da rede em exame, formados pelas conexões entre as empresas que investem as maiores quantidades de dinheiro e os candidatos que recebem a maior parte deste dinheiro. No limite, buscamos mostrar 
não apenas quem são os atores que hegemonizam uma arena decisória essencial no que se refere aos modelos de desenvolvimento no Brasil, mas os próprios vínculos entre esses atores. Ato contínuo, as questões que orientam o trabalho são: como é a estrutura da rede de financiamento dos membros da CMADS? Quais grupos de capital político-econômico se formam e se relacionam no interior dessas redes?

Trata-se de uma análise estrutural baseada em atributos relacionais dos atores pesquisados. A Análise de Redes Sociais (ARS) consolidou-se como a metodologia por excelência para uma pesquisa com tal desenho e este trabalho emprega seus instrumentos e medidas. Os dados foram coletados em duas fontes: para detecção das empresas que doaram para os deputados federais integrantes da CDMAS no período analisado (2015-2018), baixamos as planilhas de prestação de contas das candidaturas desses integrantes, nas eleições de 2014, no Repositório de Dados Eleitorais do Tribunal Superior Eleitoral (BRASIL, 2019a). Para identificação dos parlamentares que compõem nosso objeto, consultamos os relatórios de atividades da comissão, disponíveis no portal da Câmara dos Deputados (BRASIL, 2015a, 2016, 2017, 2018). Os dados foram organizados em com gerenciador de banco de dados relacional, tabulados no Excel® e analisados por meio do programa de Análise de Redes Gephi.

Vale mencionar que a eleição de 2014 apresentou características únicas: ao mesmo tempo em que foi a última a permitir doações legais de pessoas jurídicas a partidos e candidatos ${ }^{2}$, foi a primeira na qual a identificação dos doadores de recursos privados que passam pela contabilidade dos partidos políticos se tornou obrigatória. Assim, por exemplo, nas eleições anteriores, se uma empresa doasse uma determinada quantia para um partido e este a repassasse a um candidato, não havia qualquer obrigação do candidato de mencionar a fonte original (a empresa) deste recurso. É ocioso listar as dificuldades que isso gerava para a correta identificação do fluxo do dinheiro nas campanhas eleitorais, especialmente porque a maior parte das doações que os candidatos recebiam passava pelos partidos. Nesta pesquisa, todas as doações empresariais - diretas ou indiretas (via partidos ou outros comitês ${ }^{3}$ e candidaturas) - foram devidamente identificadas.

Para se ter ideia da centralidade que as empresas tinham, nas eleições de 2014, originaram-se destas organizações $\mathrm{R} \$ 3,05$ bilhões, praticamente três quartos dos $\mathrm{R} \$ 4,14$ bilhões arrecadados pelas campanhas.

\footnotetext{
${ }^{2}$ É necessário mencionar que tal proibição inicialmente veio do Poder Judiciário. Em 2015, o Supremo Tribunal Federal, no julgamento da ADI 4.650, impetrada pelo Conselho Federal da Ordem dos Advogados do Brasil (OAB), considerou procedente a petição pela proibição das doações empresariais. No mesmo ano, o Congresso Nacional tentou reintroduzir o financiamento empresarial na minirreforma política (Lei 13.165/2015), porém o dispositivo foi vetado pela então presidenta Dilma Roussef e o veto não foi derrubado. (BRASIL, 2015b).

${ }^{3}$ No Brasil, comitês são organizações criadas especificamente para gerir recursos de campanha durante o período eleitoral. Nas eleições gerais, os comitês são organizados por distritos eleitorais (União e Unidades Federativas/UFs). Além de um Comitê Financeiro Único (CFU) por partido em cada UF, existem comitês de candidaturas. Desse modo, pode haver um Comitê para Presidência da República para cada partido que lança ou apoia candidato a este cargo, além de comitês para Governador, Senador, Deputado Federal e Deputado Estadual, também para cada partido.
} 
Os motivos pelos quais empresas investem somas tão vultosas em campanhas políticas são objeto de diversas pesquisas que vêm constituindo um robusto campo de investigação - o qual apresentamos na seção teórica deste trabalho. Por ora, cumpre destacar que, com ele, pretendemos contribuir para o campo, particularmente na agenda que associa o financiamento eleitoral a payoffs visados por grupos de interesse. Mediante a identificação e a medição dos vínculos entre agentes públicos e financiadores eleitorais, perseguimos uma compreensão inicial de como esta dinâmica se constitui nas políticas públicas ambientais, a partir de um objeto privilegiado para tal fim.

Além desta introdução, o artigo tem quatro partes. A primeira é uma breve contextualização teórica sobre as interfaces entre questões ambientais e desenvolvimento, além de redes sociais e financiamento político. A segunda apresenta o desenho metodológico da pesquisa. Na terceira parte, apresentamos e discutimos os resultados empíricos. Por fim, sintetizamos esses resultados, mirando especialmente seus sentidos políticos, para o desvelamento das relações de poder em torno das políticas ambientais no Brasil.

\section{Referencial teórico-metodológico}

\subsection{Interfaces entre ambiente e desenvolvimento}

As questões ambientais começam a ganhar espaço nas agendas dos estados nacionais na virada dos anos 1970 (ALIER, 2007). Já o conceito de desenvolvimento sustentável resulta da crescente conscientização sobre o vínculo entre questões ambientais e problemas socioeconômicos (HOPWOOD et. al., 2005). O primeiro uso significativo do termo ocorreu em 1980, no World Conservation Strategy (IUCN et. al, 1980). Tanto neste documento quanto no Relatório de Brundtland (1987), verifica-se a forte preocupação com a capacidade das gerações futuras em satisfazer suas necessidades.

Gradativamente, surgem movimentos ambientais opondo-se ao discurso hegemônico que enxerga a humanidade externa ao meio ambiente e comemora o triunfo do homem sobre a natureza, com base na crença de que a prosperidade e o bem-estar globais podem ser alcançados com incremento de capital. A contemporaneidade aponta que este modelo de desenvolvimento falhou em erradicar a pobreza global, por não considerar que os laços que estabelecemos e atividades que realizamos na vida em sociedade estão inseridos no meio ambiente e que, portanto, os problemas ambientais são globais, ainda que existam localmente.

O embate entre essas duas visões assume várias classificações. Pode ser compreendido, por exemplo, a partir da distinção entre sustentabilidade fraca e forte. A primeira vai ao encontro da economia neoclássica e acredita que o capital natural é substituível pelo manufaturado, sendo a tecnologia capaz de preencher as lacunas resultantes de tal intercâmbio. A segunda defende que

o capital manufaturado não pode substituir uma multiplicidade de processos vitais para a 
existência humana como a camada de ozônio, fotossíntese e o ciclo das águas. Ao afirmarem-no, ambientalistas defendem a economia como um sistema aberto, regido pela Lei da Entropia, pelo qual, no processo de transformação de matéria-prima em produto, uma parte sempre se perde (GEORGESCU-ROEGEN, 2012, p. 83).

A necessidade de atenção às questões ambientais não significou, no entanto, consenso em torno delas, surgindo diferentes correntes ambientalistas. Hopwood et al. (2005) mapeiam os movimentos conforme o peso que fatores ambientais e questões econômicas combinados exercem na agenda das organizações. Emergem três visões distintas sobre a natureza das mudanças necessárias na política da sociedade, nas estruturas econômicas e nas relações homem-ambiente para alcançar o desenvolvimento sustentável (HOPWOOD et al., 2005, p. 5): status quo, reforma e transformação.

Defensores do status quo negam que a humanidade esteja à beira de um colapso ambiental ou social. Reconhecem a necessidade de mudança, mas não defendem a ruptura e sim ajustes que não comprometem a estrutura social e suas relações de poder. Desenvolvimento é aqui identificado como crescimento econômico, como parte da solução para erradicar problemas como a fome generalizada, por exemplo. Incentiva-se a adoção de estilos de vida mais sustentáveis por parte dos consumidores, argumentando-se que mudanças nas escolhas feitas por estes impulsionam o mercado a adotar modelos mais sustentáveis de desenvolvimento. Os defensores do status quo teriam fraco compromisso com a sustentabilidade, bem como com a vida em sociedade e a desconcentração de poder, preferindo preservar a estabilidade macroeconômica por meio de "reformas amigáveis" (HOPWOOD et al., 2005).

Reformistas se opõem à maioria das empresas, governos e tendências dentro da sociedade, porém o enfrentamento não é radical. Em geral, assumem que mudanças profundas na política e no estilo de vida das sociedades serão necessárias em algum momento, mas preferem adotar medidas de longo prazo e dentro das estruturas sociais e econômicas existentes. A estratégia é persuadir governos e organizações internacionais a introduzir as reformas necessárias. Grupo amplamente dominado pelo terceiro setor, crê nos benefícios da tecnologia para o meio ambiente, em alternativas para reduzir o uso de matéria-prima na economia e na eficiência energética para utilizar fontes renováveis de energia.

Já os transformacionistas compartilham a visão de que as crescentes crises no meio ambiente e na sociedade estão interligadas e que os sistemas socioambientais correm o risco de ruptura. Tais problemas possuem raízes profundas na sociedade atual e sua forma de organização, baseada na exploração da maioria das pessoas e do meio ambiente por um pequeno grupo, que não está verdadeiramente interessado no bem-estar humano ou na sustentabilidade ambiental. Este campo inclui movimentos com preocupações exclusivamente ambientais, outros preocupados somente com as transformações sociais e aqueles que sintetizam os dois objetivos (HOPWOOD et al., 2005). A estratégia, neste caso, é trazer populações marginalizadas como 
grupos indígenas, os pobres, a classe trabalhadora e mulheres para o centro das ações (HOPWOOD et al., 2005, p. 8).

Nota-se, portanto, uma transformação importante no debate que articula questões ambientais e o desenvolvimento, especialmente quando voltamo-nos à sua constituição primitiva, subsumida na noção de progresso (FURTADO, 1978), decorrente das revoluções burguesas que, a partir do fim do século XVIII, instituíram o racionalismo e o empirismo como nova base da legitimidade do conhecimento, não mais assentada na fé. Como reverso da medalha, o progresso emerge como símbolo para exercer domínio sobre outras culturas. Aquilo que constituía nada além de "uma entre as muitas formas de vida social, tornou-se por definição o estágio final de um caminho unilinear para a evolução social” (SACHS, 2000, p. 63).

No entanto, "para que aqueles que constituem os dois terços da população mundial atual possam pensar em desenvolvimento - qualquer tipo de desenvolvimento - é preciso em primeiro lugar que se vejam como subdesenvolvidos, com o fardo total de conotação que o termo carrega (SACHS, 2000, p. 61). Assim, o conceito de "subdesenvolvido" acaba por se tornar um símbolo tão forte quanto a ideia de desenvolvimento, esta última, em seu sentido positivo, "é um eterno lembrete daquilo que eles não são" (SACHS, 2000, p. 65), com o poder de impor às nações enormes sacrifícios diante da promessa de um padrão de vida ostentado nos países de "Primeiro Mundo".

A preocupação de Furtado (2013) recai sobre o fosso que o processo de acumulação inerente ao sistema capitalista - provoca entre um centro e uma constelação de economias periféricas e seus efeitos de pressão sobre os recursos não renováveis, diante da crescente homogeneização de um padrão de vida consumista gerador de grandes custos ambientais. $\mathrm{O}$ autor prevê que, as custas da depredação do mundo físico, qualquer tentativa de generalizar o estilo de vida ostentado nos países cêntricos representaria o colapso de toda uma civilização. Portanto, nesses termos o desenvolvimento não passa de um mito que auxilia de forma determinante na promoção da dinâmica díade opressão-acumulação.

Apontamentos sugerem que os frutos do desenvolvimento não são compartilhados de forma igualitária. Esse fluxo desigual de recursos se projeta tanto na macrorrelação entre estados nacionais, quanto dentro dos próprios países. Nesse sentido é possível vislumbrar a hipótese de que, no Brasil, os grupos que se beneficiam do atual modelo de desenvolvimento tenham especial interesse nas matérias discutidas dentro da Comissão do Meio Ambiente e Desenvolvimento Sustentável (CMADS).

No centro desse debate está a qualidade dos governos em garantir instituições eficazes em suas atribuições, uma vez que o estado tem papel mediador e compensador entre a sociedade e as correções de disparidades provocadas pelo mercado, além da responsabilidade pela gestão de recursos não reprodutíveis de uso comum. Thomas et. al (2002) reconhecem o enfoque na estrutura institucional para um bom governo como um princípio chave para o desenvolvimento. 
Segundo os autores, bons resultados sociais são encontrados em países com instituições governamentais efetivas, "onde as políticas e a estrutura legal não foram tomadas pelos investimentos de capital da elite" (THOMAS et. al, 2002, p. 142). Contudo, os governos têm dado atenção insuficiente às supervisões do setor financeiro e meio ambiente.

Estas evidências tornam pertinente a investigação da possível ocorrência do fenômeno de captação de política reguladora por grupos de interesses dentro da CMADS, visto que dentre as funções da comissão está regular acerca de políticas e sistema nacional do meio ambiente, direito ambiental e legislação de defesa ecológica. Além disso, a abundância de recursos naturais, como água e petróleo, no Brasil atrai capital estrangeiro. Esse efeito refere-se a processos de competição e entrada, sendo que a quebra de monopólios e a facilitação de entrada e saída poderiam ser instrumentos de combate ao solapamento de recursos naturais por monopólio de empresas.

Apesar de a obra trazer contribuições valiosas no debate de como a qualidade do governo afeta os resultados de desenvolvimento, certos esclarecimentos precisam ser feitos. Em primeiro lugar porque os autores lançam mão de termos como "países em desenvolvimento" e recorrem a receituários para que países que se enquadram nessa categoria possam atingir o patamar dos desenvolvidos países do norte, reforçando uma dicotomia Norte-Sul já posta em xeque por Furtado (2013). Em segundo lugar, em vista da frouxidão do conceito "desenvolvimento sustentável", por conta da confusão entre os termos "desenvolvimento" e "crescimento", vislumbramos a necessidade de conceituar cada um deles e, assim, diferenciá-los.

Ao passo que Thomas et. al (2002, p. 24) alertam para as dimensões qualitativas e quantitativas do crescimento, Daly (2004) afirma que essas dimensões são de tal forma diferentes que surge a necessidade de dar a cada uma delas um nome, uma vez que crescer significa aumentar de tamanho através da assimilação ao acréscimo de material, enquanto que desenvolver-se diz respeito a expansão na realização dos potenciais, assim: "Quando algo cresce fica maior. Quando algo se desenvolve torna-se diferente”. (DALY, 2004, p. 198)

Dessa forma, crescimento refere-se à atividade de manufatura de recursos naturais, transformados em produtos, vendidos e posteriormente descartados. O ecossistema, pelo contrário, não cresce, apenas desenvolve-se, ao passo que a economia não para de crescer, num mundo de recursos finitos. Caberia então perguntar se é possível equilibrar crescimento econômico ilimitado com preservação do meio ambiente. Para Cavalcanti (2012) a resposta é negativa: "crescimento implica sempre menos meio ambiente. De fato, o planeta (o ecossistema global) não cresce; se a economia cresce - e ela é parte do planeta -, obviamente menos meio ambiente restará" (CAVALCANTI, 2012, p. 37). Assim, não pode haver crescimento sustentável.

Nesse sentido, Sachs (2000) define desenvolvimento sustentável como sendo uma abordagem fundamentada na harmonização dos objetivos sociais, ambientais e econômicos do desenvolvimento. Criticando o que ele chama de "crescimento selvagem" que explora modelos extrativistas de crescimento econômico e recursos ambientais não renováveis, mas também os 
modelos protecionistas do fundamentalismo ambiental, Sachs (2000) instiga países emergentes a procurar o "caminho do meio", do crescimento reformulado em relação à modalidade de uso, apostando no conhecimento técnico como "saída" para a dicotomia entre economia e ecologia.

\subsection{Redes sociais e financiamento eleitoral}

Para a Análise de Redes Sociais (ARS) - também chamada de análise estrutural - a estrutura social não é um dado a priori, mas sim uma rede de relações e pressões na qual os atores sociais necessariamente se posicionam e se definem em função dos laços que estabelecem (ou deixam de estabelecer) com outros atores na rede (DEGENNE; FORSE, 2007). Nesse sentido, o foco central desta metodologia são os atributos relacionais que posicionam indivíduos e grupos em teias de interações (HIGGINS; RIBEIRO, 2018), em vez de seus atributos estáticos como as variáveis sociodemográficas (gênero, raça, renda, escolaridade etc.) comuns à maioria das abordagens da vida social e com as quais se caracterizam e até se comparam atores, de maneira mais ou menos agregada, porém como unidades isoladas no tecido social.

Os estudos embrionários com a metodologia de redes remontam aos anos 1930, podendose fixar seu início com os sociogramas de Moreno (1942), no âmbito da psicologia experimental, que visavam à identificação de laços entre pequenos grupos/círculos de sociabilidade. Os avanços tecnológicos na área de armazenamento e análise de dados permitiram o gradual avanço das pesquisas para grupos maiores e mais complexos. Paulatinamente, a análise de redes revelou um mundo pequeno, que conecta entre si quase todos os membros de uma sociedade, ainda que indiretamente ${ }^{4}$.

Com efeito, à luz das contribuições de Georg Simmel, a ARS mostrou que, em torno de uma pessoa, constitui-se uma rede (rede ego), composta de círculos sociais concêntricos formados por outras pessoas, que por sua vez têm suas próprias redes ego, com outras pessoas, e assim sucessivamente (DEGENNE; FORSE, 2007). Uma consequência desta descoberta é a necessidade de se estudar redes completas, como soma das múltiplas redes de pessoas interconectadas, não havendo como fazer investigações adequadas a partir de amostras na metodologia em questão.

A análise de redes sociais é um paradigma que articula elementos das teorias holísticas e o individualismo metodológico, na medida em que ela, a despeito de seu caráter estrutural e sistêmico, parte do pressuposto de que agência humana tem a capacidade de atuar sobre a estrutura social. Esta, num processo de retroalimentação, delimita o campo de ação dos atores, a partir de

\footnotetext{
${ }^{4}$ É o que demonstrou o experimento de Milgram (1967), realizado na década de 1960 e pelo qual voluntários de regiões diferentes dentro dos EUA tinham de fazer uma correspondência chegar a alguém desconhecido em uma cidade distante, remetendo-a a alguém que supunham que pudesse conhecer a pessoa. Considerando as cartas que efetivamente chegaram a seus destinatários, havia em média de cinco pessoas entre os remetentes iniciais e os destinatários finais. Um número pequeno e impressionante para uma sociedade de massas, à época formada por quase 200 milhões de habitantes dispersos em um território de mais de 9 milhões de $\mathrm{km}^{2}$.
} 
seus recursos e estratégias. É, porém, alterada pelo comportamento daqueles por ela constrangidos (MIRZUCHI, 2006). Com isso, a ARS possibilita algo que, por muito tempo, o campo hegemônico da ciência política viu com marcado ceticismo ${ }^{5}$, que é a identificação empírica de elites de poder a partir das relações mais próximas e intensas entre seus integrantes.

Elites de poder são grupos que dominam a agenda política de uma sociedade. Dominar aqui significa querer e conseguir influenciar intencionalmente os resultados de processos decisórios que envolvem as políticas públicas que, no limite, determinam o que se pode e o que não se pode fazer e a alocação de recursos públicos. Grupos dominantes não são compostos apenas pelos agentes que detêm a prerrogativa formal de decidir, mas também (talvez principalmente) por aqueles que, por vezes agindo em outros círculos, têm grande capacidade de determinar quem serão os referidos agentes e que temas são dignos de se converterem em problemas públicos, pautas e decisões (MILLS, 1981 [1956]; SCHATTSCHNEIDER, 1988). Conglomerados empresariais que financiam a política se encaixam perfeitamente neste perfil. As redes de poder e influência são formadas por diversos tipos de atores sociais e suas posições em uma rede importam para se determinar sua influência potencial sobre outros atores e, ato contínuo, as próprias agendas (DEGENNE; FORSE, 2007).

Quando se mencionam elites, deve-se fazê-lo no plural, pois não há um único grupo de atores individuais ou coletivos que domine as agendas políticas de maneira absoluta ou mesmo permanente. Nesse sentido, tarefa essencial de quem estuda processos decisórios à luz da análise estrutural ora em discussão é prospectar que subgrupos se formam no interior das redes de poder, na medida em que "os atores formam blocos entre si no interior dos quais as relações são positivas e entre os quais as relações são negativas" (LEMIEUX; OUIMET, 2014, p.58). A grupabilidade é, portanto, um princípio caro à teoria de redes. Por ela, agentes tendem a aproximar-se daqueles com quem têm afinidades eletivas, compartilhando e sustentando identidades (WHITE, 1992).

No que concerne a esta pesquisa, cabe verificar se o fenômeno da grupabilidade ocorre na rede de financiamento que constitui a bancada de deputados componente da CMDAS, na $55^{\text {a }}$ legislatura (2015-2018). Com isso, é possível saber se os grupos de capital político-econômico formam comunidades organizadas em torno de seus interesses, quando direcionam recursos financeiros para um ou mais candidatos/partidos em comum.

Esta pesquisa insere-se na florescente agenda de investigações que aplicam a Análise de Redes Sociais no estudo de fenômenos políticos no Brasil. Da extensa lista de objetos investigados, vale mencionar as redes de atores que ocupam e concentram posições em instituições do Estado (MARQUES, 1999; PERISSINOTTO et al., 2017), as redes constituídas nas interações entre governo, políticas públicas e sociedade civil (LAVALLE; CASTELLO; BICHIR, 2007), os relacionamentos entre parlamentares no Congresso Nacional (WOLF, 2008),

\footnotetext{
${ }^{5}$ Veja-se, por exemplo, o trabalho inicial de Dahl (1961).
} 
as relações de grupos empresariais com agentes políticos, no contexto de financeirização do capital (MINELLA, 2013), as redes formadas por deputados federais e suas proposições (PAZ, 2015), entre outros.

No campo mais específico do financiamento político, a metodologia de redes vem sendo utilizada, nos últimos anos, com vistas à prospecção dos vínculos estabelecidos entre doadores, partidos e candidatos (CERVI; HOROCHOVSKI; JUNCKES, 2014; HOROCHOVSKI et al., 2016; JUNCKES et al., 2018). Vale mencionar ainda pesquisas que, à semelhança desta, cotejam as redes de financiamento eleitoral e a composição das comissões permanentes da Câmara dos Deputados (HOROCHOVSKI et al., 2017; GEARA et al., 2018).

A introdução da ARS no campo de pesquisa sobre financiamento político resulta dos fatores que viabilizaram a própria existência deste campo investigativo no Brasil. Diferentemente do que ocorreu nos EUA, por exemplo, onde há décadas pesquisadores vêm demonstrando a força da relação entre o dinheiro e a política (JACOBSON, 1978; WELCH, 1981), eram escassos os estudos sobre a situação brasileira até o início do século XXI. A razão principal residia na dificuldade de obtenção dos dados de prestação de contas eleitorais no país. Assim mesmo, fazse necessário destacar trabalhos pioneiros sobre eleições ocorridas nos anos 1990, notadamente os de Samuels $(2001,2002)$.

O ponto de inflexão foi a disponibilização na internet, a partir das eleições de 2002, de todos os dados de financiamento legal de campanhas no Brasil pelo Tribunal Superior Eleitoral (TSE), em seu Repositório de Dados Eleitorais. As pesquisas se multiplicaram rapidamente, podendo-se então falar em um campo específico de investigações, cujo balanço mais conhecido sobre a produção brasileira é o de Mancuso (2015). Este autor identificou três principais correntes investigativas:

1) Relação entre recursos financeiros e desempenho eleitoral (SAMUELS, 2001; FIGUEIREDO FILHO, 2009; PEIXOTO, 2016; LEMOS; MARCELINO; PEDERIVA, 2010; CERVI; 2010; MANCUSO; SPECK, 2012);

2) Associação entre doações de campanha e payoffs buscados pelos doadores (ARAÚJO, 2008; ROCHA, 2011; SANTOS, 2011; BOAS; HIDALGO; RICHARDSON, 2014);

3) Variáveis sociais e políticas determinantes do financiamento eleitoral (SAMUELS, 2002; MELLO; MARCON; ALBERTON, 2008; SANTOS, 2009; SACCHET; SPECK, 2011). As pesquisas dessas três vertentes revelam que o financiamento eleitoral no Brasil está longe de ser equitativo, representando uma barreira à qualidade da democracia nos termos apresentados na introdução deste trabalho. A primeira demonstra a forte correlação entre as quantidades de dinheiro e votos recebidas por candidatos e partidos. A segunda vem tentando comprovar que os financiados pelos grupos de capital são mais responsivos aos interesses destes grupos. A terceira vertente, por sua vez, mostra que os candidatos e partidos que mais recebem doações têm perfil determinado: estes são as agremiações de maior porte, independentemente de 
sua posição do espectro ideológico esquerda-direita, enquanto aqueles são quase sempre homens, brancos, ricos, altamente escolarizados e detentores de capital político prévio.

Nossa investigação se dedica a contribuir com a segunda vertente apontada por Mancuso (2015), na medida em que visamos justamente a identificar grupos empresariais vinculados a deputados federais que integram uma arena decisória importante. Tal identificação é um passo inicial, necessário ao escrutínio mais denso da atuação dos parlamentares mais diretamente envolvidos com as políticas públicas ambientais vis-à-vis os interesses de seus financiadores. $\mathrm{Na}$ próxima seção, descrevemos como a pesquisa empírica foi realizada.

\section{Materiais e métodos: como a pesquisa empírica foi feita}

A pesquisa empírica iniciou-se com a coleta dos dados, a partir de duas fontes:

1) Repositório de Dados Eleitorais do TSE: nesta fonte, obtivemos as planilhas com os perfis das candidaturas e a prestação de contas de campanhas dos deputados federais que se elegeram em 2014 (BRASIL, 2019a). No site do tribunal, esses dados estão dispostos por unidade federativa, o que resulta em 54 diferentes planilhas. Uma primeira tarefa foi, então, compilar todo o material em um banco de dados, com o gerenciador PostgreSQL. Sobre o banco resultante, aplicamos um filtro, selecionando todos os candidatos a deputado federal e seus doadores empresariais diretos e indiretos ${ }^{6}$.

2) Relatórios das atividades legislativas da Comissão de Meio Ambiente e Desenvolvimento Sustentável (CMDAS), disponíveis no sítio eletrônico da Câmara dos Deputados: com esta fonte, identificamos os deputados federais que integraram a comissão, na 55 Legislatura (2015-2018) e os tabulamos em planilhas (BRASIL, 2015a, 2016, 2017, 2018). Estabelecemos nesta etapa uma linha de corte, de 180 dias de atuação. Como resultado, 68 parlamentares preencheram este requisito. A seguir, os nomes dos deputados foram filtrados no banco de dados de prestação de contas e perfil de candidaturas. Um dos 68 deputados inicialmente selecionados declara em sua prestação de contas não ter recebido qualquer doação de empresa, restando, portanto 67 parlamentares que cumprem ambos os critério, ou seja, mais de 180 de atuação na CMADS e recebimento de recursos de empresas na campanha de 2014.

Redes são conjuntos de nós e arestas. Em redes sociais, os nós são os atores sociais e as arestas, os laços que os vinculam. No caso estudado, os atores são os deputados federais que compuseram a CMADS por pelo menos 180 dias e as empresas que doaram para suas campanhas, direta ou indiretamente (via partidos, outros candidatos e comitês). Os laços são estabelecidos pelas doações, as quais, portanto, conectam os parlamentares aos financiadores de suas

\footnotetext{
${ }^{6}$ Como dissemos anteriormente, nas eleições de 2014, foi possível identificar os doadores originários das doações que chegaram aos candidatos via partidos ou outros candidatos e comitês. Para esta pesquisa, consideramos todas essas doações e aquelas feitas diretamente pelas empresas aos candidatos como doações empresariais e todas as empresas que as efetuaram foram corretamente identificadas.
} 
campanhas. Para processar esta rede, empregamos o programa Gephi, com o qual geramos estatísticas de centralidade e os grafos da rede.

Fizemos ainda dois outros procedimentos analíticos. O primeiro foi a detecção de comunidades (clusters) por meio do cálculo de modularidade, com o qual operacionalizamos a identificação dos subgrupos de atores com maior proximidade entre si, a que nos referimos na seção anterior (BLONDEL et al., 2008). O segundo, a transformação da rede, que é bimodal pois apresenta dois tipos de atores, as empresas doadoras e os deputados receptores - em duas redes unimodais ${ }^{7}$, por meio da supressão de cada um dos nós intermediários entre dois atores de um determinado tipo, ligando-os de modo direto. Construímos, assim, uma rede com parlamentares diretamente ligados entre si e outra, com conexões diretas entre financiadores diretamente. Com isso, é possível obter uma melhor visualização dos metarrelacionamentos entre atores do mesmo tipo, a partir da afirmação, bastante corriqueira no senso comum, de que "o amigo do meu amigo é meu amigo". Assim, por exemplo, deputados financiados pelos mesmos doadores tenderiam a compor o mesmo círculo de sociabilidade e transação de recursos.

Os resultados da aplicação desses procedimentos são apresentados a seguir, juntamente com explicações mais pormenorizadas das variáveis e medidas de rede.

\section{Resultados: CMADS como lócus de entrecruzamento e articulação de interesses empresariais}

A Figura 1 abaixo é o grafo da rede de financiamento que conecta deputados federais membros da Comissão de Meio Ambiente e Desenvolvimento Sustentável, durante a $55^{\text {a }}$ Legislatura e as empresas que o financiaram (doravante, a denominamos Rede CMADS). Esta rede é formada por 67 parlamentares e 860 pessoas jurídicas, conectados por 1.164 arestas. As arestas correspondem às doações agrupadas, todas as doações de uma empresa para um candidato foram juntadas em uma única aresta, somando-se os valores, já que, para nós, interessam os vínculos entre financiadores e financiados e sua intensidade. O tamanho dos nós está dimensionado pelo volume de recursos doados ou recebidos (weighted degree) e espessura das

\footnotetext{
${ }^{7}$ Sobre o recurso de conversão dual-mode / one-mode consultar Newman (2010, p. 124-126).
} 
arestas está dimensionada pelo volume de recursos transacionados entre os nós.

Figura 1 - Rede CMADS

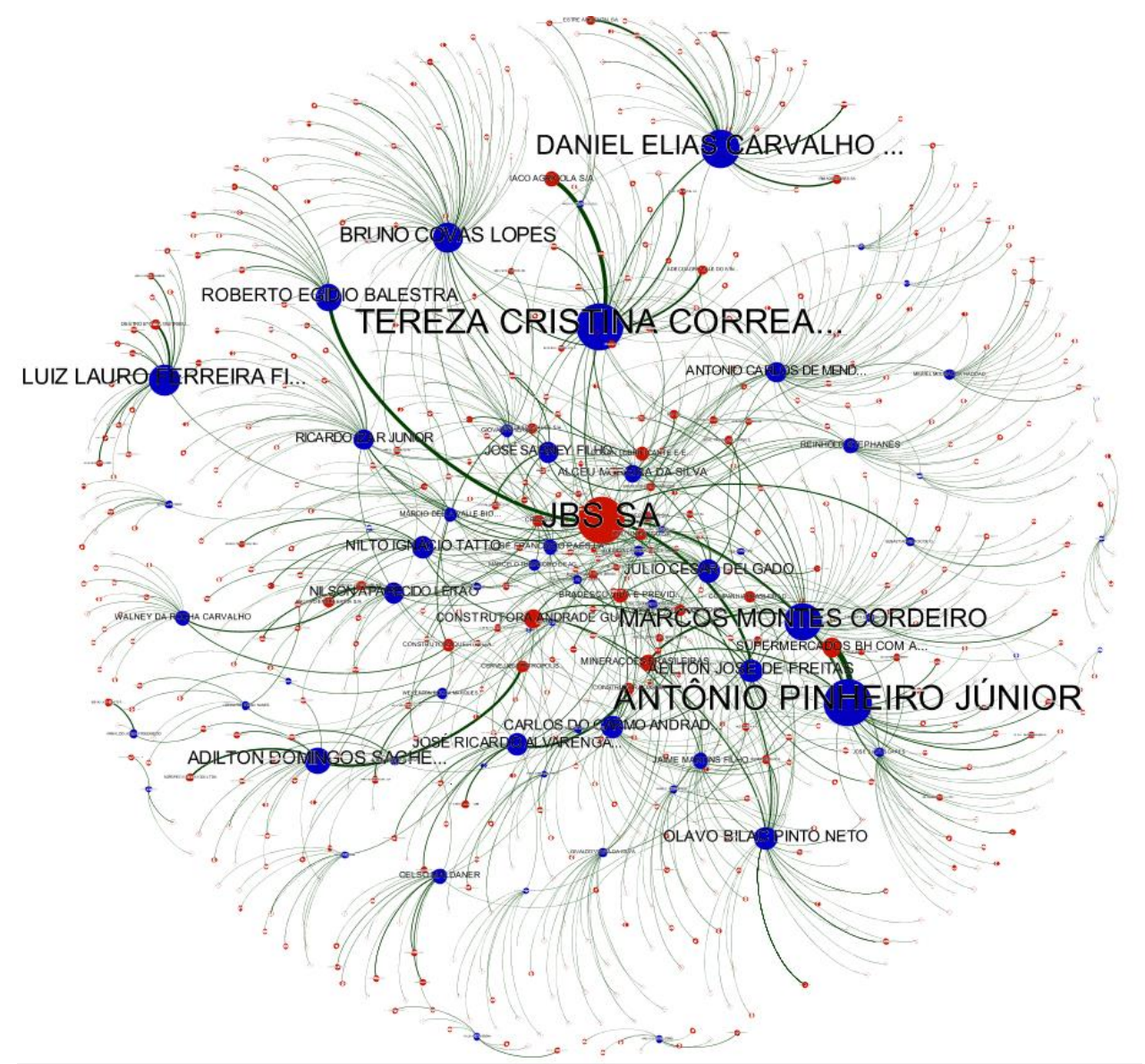

Fonte: Elaboração própria, com dados do TSE (BRASIL, 2019a) e da Câmara dos Deputados (BRASIL, 2015a, 2016, 2017, 2018).

O peso somado das arestas é 59.180.437, o que corresponde ao montante total, em reais, que as empresas doaram aos deputados pesquisados. Desse modo, cada parlamentar recebeu em média R \$ 883.290 de pessoas jurídicas. Os valores estão, no entanto, distribuídos de maneira muito dispersa (desvio padrão $=R \$ 959.576$ ), variando entre $R \$ 275$ e $R \$ 4.068 .302$, sendo a mediana $\mathrm{R} \$ 483.910$. A estatística descritiva já sinaliza uma rede muito desigual, assimétrica e hierarquizada. As análises subsequentes apresentam a posicionalidade dos atores nesta hierarquia.

A primeira análise é a de componentes, que são conjuntos de nós conectados entre si, direta ou indiretamente. Segundo a ARS, há uma tendência de redes grandes e complexas apresentarem um componente gigante, que reúne a grande maioria ou a quase totalidade dos nós, e diversos componentes menores, que conectam poucos nós ou são nós isolados, sem laços com outros (FREEMAN, 1979; NEWMAN, 2010). A Rede CMADS segue a tendência e seu 
componente gigante concentra 888 (95,8\%) dos 927 nós da rede (TABELA 1).

Tabela 1 - Componentes da Rede CMADS (frequências)

\begin{tabular}{|c|c|c|c|c|c|c|c|}
\hline \multicolumn{2}{|c|}{ Rede-base } & \multicolumn{2}{|c|}{ 06 Componentes Isolados } & \multirow{2}{*}{$\begin{array}{r}\begin{array}{c}\% \\
\text { rede } \\
\text { base }\end{array} \\
4,2\end{array}$} & \multicolumn{2}{|c|}{ Componente Gigante } & \multirow{2}{*}{$\begin{array}{c}\% \\
\begin{array}{c}\% \\
\text { rede } \\
\text { base }\end{array} \\
95,8\end{array}$} \\
\hline Total de Nós & 927 & Total de Nós & 39 & & Total de Nós & 888 & \\
\hline $\begin{array}{l}\text { Deputados } \\
\text { federais }\end{array}$ & 67 & $\begin{array}{l}\text { Deputados } \\
\text { federais }\end{array}$ & 6 & 8,9 & $\begin{array}{l}\text { Deputados } \\
\text { federais }\end{array}$ & 61 & 91,1 \\
\hline Empresas & 860 & Empresas & 33 & 3,8 & Empresas & 827 & 96,2 \\
\hline Arestas & 1164 & Arestas & 33 & 2,9 & Arestas & 1.131 & 97,1 \\
\hline $\begin{array}{l}\text { Valor } \\
\text { transacionado }(\mathrm{R} \$)\end{array}$ & 59.180 .437 & $\begin{array}{l}\text { Valor } \\
\text { transacionado }(\mathrm{R} \$)\end{array}$ & 802.028 & 1,3 & $\begin{array}{l}\text { Valor } \\
\text { transacionado }(\mathrm{R} \$)\end{array}$ & 58.378 .409 & 98,6 \\
\hline
\end{tabular}

Fonte: Elaboração própria, com dados do TSE (BRASIL, 2019a) e da Câmara dos Deputados (BRASIL, 2015a, 2016, 2017, 2018).

Os seis demais componentes, que denominamos isolados, possuem entre dois e 12 nós. Não nos debruçamos mais detidamente sobre estes componentes. Todavia, sua composição indica um aspecto importante, que são os atores completamente marginalizados da rede de financiamento. São seis deputados federais (cada um em um componente) e 33 empresas, que constituem sub-redes de financiamento próprias. Chama a atenção a presença dos dois únicos parlamentares do Partido Socialismo e Liberdade (PSOL) ${ }^{8}$ a compor a comissão na legislatura analisada - Edmilson Rodrigues (PA) e Ivan Valente (SP) - cada um em seu próprio componente, tendo o primeiro recebido doações de duas pessoas jurídicas e o segundo, de apenas uma, sendo as três de pequeno porte e sem doações a outros candidatos.

O componente gigante da rede é alvo de nosso exame mais detalhado, cujo primeiro passo é a aplicação de um filtro, eliminando todos os nós com grau ${ }^{9}=1$, ou seja, que estão conectados a um único outro nó, correspondendo essa conexão a uma única doação, realizada ou recebida. Assim procedemos porque nosso foco são as empresas com capacidade conectora (hub) através das doações realizadas para dois ou mais parlamentares. Encontram-se nesta condição cinco deputados federais e 698 pessoas jurídicas, correspondente a 8,2\% e 84,4\% dos respectivos tipos de nó do componente. Aqui é possível inferir uma primeira característica topológica, que é a centralidade dos parlamentares na rede, na medida em que o filtro preserva quase todos eles, ao passo que suprime a grande maioria das empresas, quase sempre de escopo regional, que fizeram

\footnotetext{
${ }^{8}$ Os partidos dos parlamentares citados ao longo do trabalho são aqueles pelos quais eles foram eleitos em 2014. A lista das agremiações e seus nomes encontra-se anexa, ao fim do texto.

${ }^{9}$ Grau é a medida de centralidade mais básica. Simplesmente expressa o número de arestas ligadas a um nó, ou, dito de outra maneira, o número de outros nós com os quais um nós se conecta. O conjunto formado por um nó e seus vizinhos imediatos é chamado de Rede Ego (DEGENNE; FORSE, 2004).
} 
apenas uma doação. Os nós removidos são, de fato, os atores periféricos do componente gigante, aqueles que não promovem qualquer conectividade.

Optamos, portanto, pela retirada de uma camada superficial da rede, posicionando nossa lupa sobre os demais atores, com grau $\geq 2$ e que, portanto, realizaram ou receberam duas ou mais doações, detendo algum potencial de conexão inter-atores (se empresa, liga deputados, e viceversa) e constituem o core. Esta rede reduzida tem 58 deputados e 115 empresas, que doaram R\$ 29.130.012 para esses parlamentares, valor correspondente a 49,2\% do valor total da Rede CDMAS (ou seja, com todos os componentes).

No grafo do componente gigante reduzido (Figura 2), os nós estão dimensionados pelo grau ponderado, medida de centralidade que considera os pesos das arestas - neste caso, o volume de dinheiro transacionado pelo ator, seja doando, seja recebendo. Os deputados federais destacamse visivelmente. Observando o grupo dos 15 principais receptores de recursos, algumas características sobressaem: o Partido do Movimento Democrático Brasileiro (PMDB) ${ }^{10}$ é o partido com maior número de representantes (três). Cinco partidos têm dois representantes (Partido Progressista - PP, Partido da República - PR, Partido Socialista Brasileiro - PSB, Partido Social Democrático- PSD e Partido da Social Democracia Brasileira - PSDB). Democratas - DEM e Partido Dos Trabalhadores - PT têm um deputado neste grupo. Minas Gerais é o estado com mais parlamentares (seis), seguido de perto por São Paulo (quatro). Parte significativa dos nomes mais salientes no grafo (os rótulos também estão dimensionados pelo grau ponderado) caracteriza-se por ter fortes vínculos com a defesa de pautas do agronegócio e laços fracos com a defesa de uma agenda de preservação ambiental e desenvolvimento sustentável.

\footnotetext{
${ }^{10}$ Para os propósitos desta investigação, consideramos os partidos pelos quais os deputados federais disputaram a eleição em 2014, dado que a rede de financiamento se constituiu neste processo.
} 
Figura 2 - Grafo do componente gigante reduzido em grau 2 da rede de financiamento dos deputados federais membros da CMADS (2011-2014)
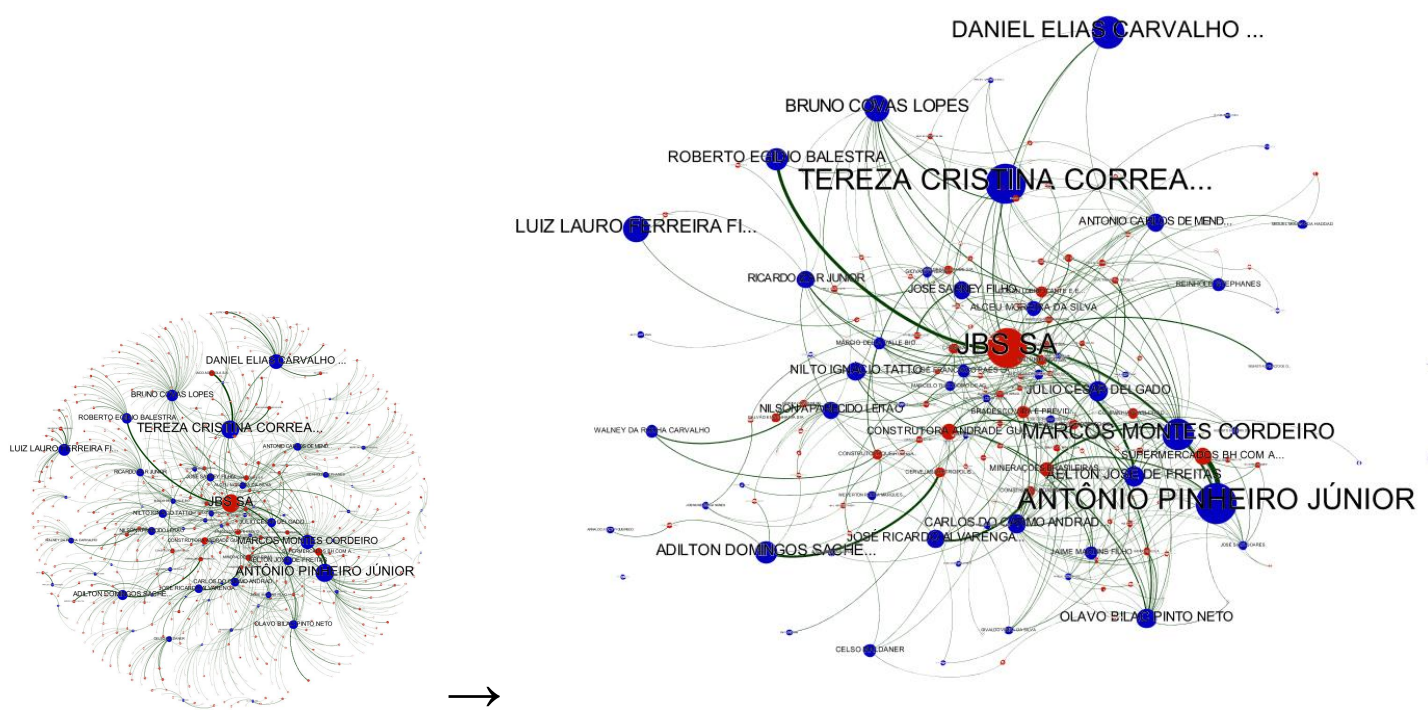

Fonte: Elaboração própria, com dados do TSE (BRASIL, 2019a) e da Câmara dos Deputados (BRASIL, 2015a, 2016, 2017, 2018).

Entre as empresas, JBS S/A exerce nítida centralidade, na medida em que suas doações aos deputados que comporiam a CMADS na $55^{\mathrm{a}}$ legislatura totalizaram pouco mais de quatro milhões de reais. À exceção de uma empresa de expressão local (Supermercados BH comércio de Alimentos LTDA), todas as demais que estão entre as 15 maiores doadoras compõem grandes conglomerados empresariais, representando os setores econômicos que historicamente são os principais doadores de campanhas no Brasil, como construção civil, mineração, produção de alimentos e finanças ${ }^{11}$. Citamos algumas dessas corporações, todas de capital aberto: Construtora Andrade Gutierrez S/A, Minerações Brasileiras S/A, Bradesco Vida e Previdência S/A, Cosan Lubrificante e Especialidades S/A, CRBS S/A, Construtora Queiroz Galvão S/A e Companhia Brasileira de Metalurgia e Mineração.

Embora os nós do núcleo duro formado pela rede reduzida componham um único componente e, por isso mesmo, estejam todos conectados, eles não formam um único grupo coeso, podendo-se identificar conjuntos de atores, vale dizer, deputados e empresas, mais próximos. Para tanto, aplicamos o cálculo de modularidade (com resolução $=2,0$ ), obtendo sete

\footnotetext{
${ }^{11}$ Dados podem ser encontrados nos trabalhos de Mancuso et al. (2016); Mancuso, Horochovski e Camargo (2018).
} 
diferentes comunidades. A Figura 3 é o grafo desta rede.

Figura 3 - Grafo do componente gigante reduzido em grau 2 distribuído por modularidade

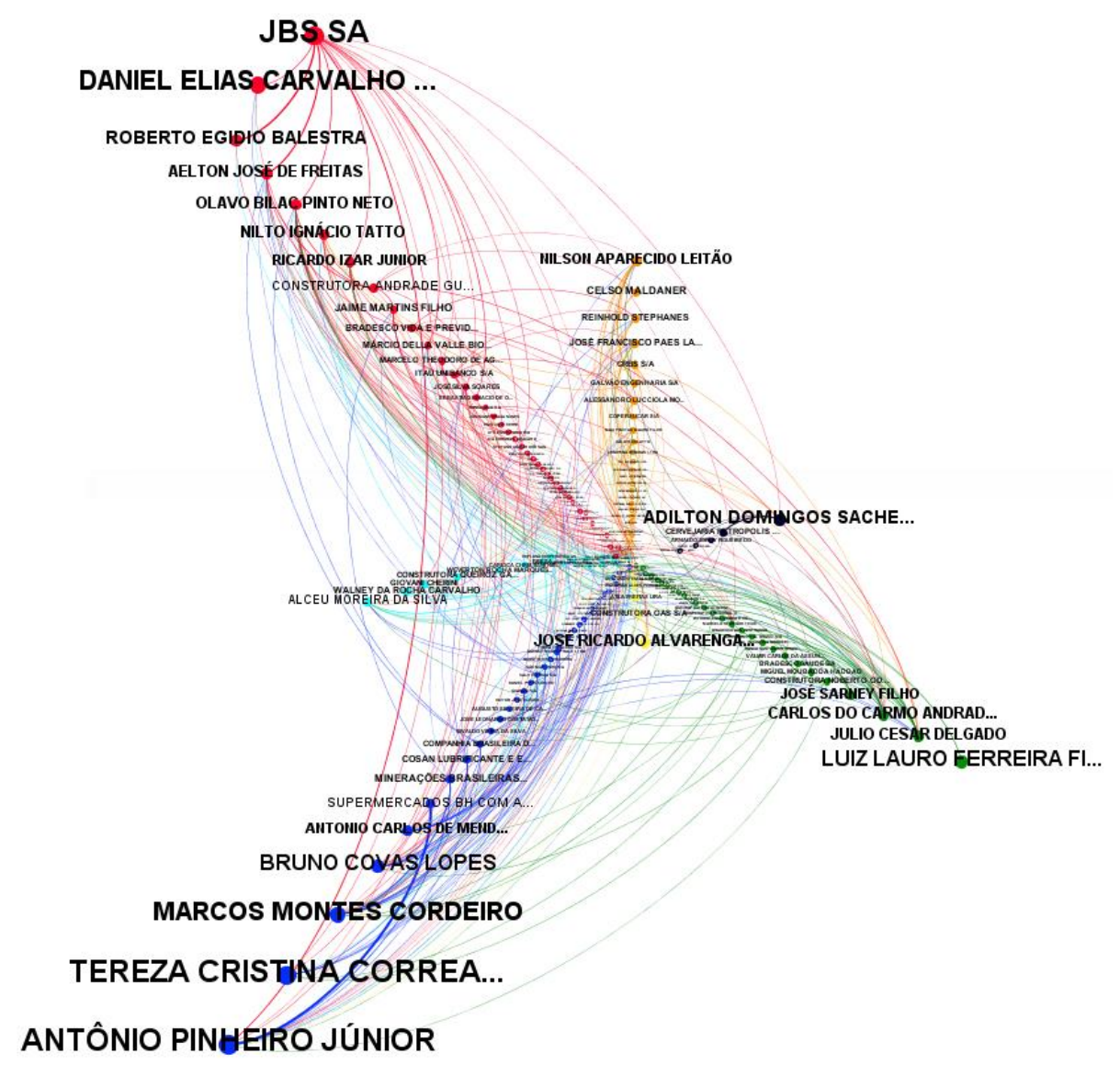

Fonte: Elaboração própria, com dados do TSE (BRASIL, 2019a) e da Câmara dos Deputados (BRASIL, 2015a, 2016, 2017, 2018)

No layout escolhido do grafo representado na Figura 3, cada raio é uma comunidade. Os atores mais centrais estão destacados pelos nós e rótulos maiores, nas pontas dos raios. Como era de se esperar, a composição das comunidades confirma a maior centralidade exercida pelos parlamentares nesta rede de financiamento. À exceção da comunidade vermelha, cujo nó central é a JBS-SA, todas as posições principais das quatro comunidades maiores (com pelos menos 20 nós) são ocupadas por parlamentares. Listamos a seguir os três deputados e as três empresas com maior centralidade de cada comunidade:

- Comunidade Vermelha: Daniel Elias Carvalho (PMDB-MG), Roberto Egídio Balestra (PP-GO), Aélton José de Freitas (PR-MG) - JBS-SA, Andrade Gutierrez S/A e Itaú Unibanco S/A.

- Comunidade Azul: Antônio Pinheiro Junior (PP-MG), Tereza Cristina Correa da Costa Dias (PSB-MS) e Marcos Montes Cordeiro (PSD-MG) - Supermercados BH 
Comércio de Alimentos Ltda, Minerações Brasileiras S/A e Cosan Lubrificante e Especialidades S/A.

- Comunidade Verde: Luiz Lauro Ferreira Filho (PSB-SP), Júlio César Delgado (PSBMG) e Carlos do Carmo Andrade Melles (DEM-MG) - Construtora Noberto Odebrecht, Bradesco Saúde S/A e Spal Indústria Brasileira de Bebidas.

- Comunidade Laranja: Nilson Aparecido Leitão (PSDB-MT), Celso Maldaner (PMDB-SC) e Reinhold Stephanes (PSD-PR) - CRBS S/A, Galvão Engenharia e UTC Engenharia S/A.

Da descrição acima, deriva a questão de por que empresas de setores tão diversos, a princípio distantes das pautas da comissão, são os principais financiadores de seus integrantes, estes também muito diversos, representando partidos de diferentes ideologias e posicionamentos em relação à agenda da CMADS, ainda que haja maior número de deputados de partidos do centro à direita nas posições centrais ${ }^{12}$.

Ao que parece, reservas ideológicas estariam vinculadas ao porte do partido, dado que se voltam exclusivamente ao PSOL, único pequeno partido de esquerda com representação na legislatura analisada e que sequer teve representante no componente gigante da rede de financiamento da CMADS. A presença de deputados de pequenos partidos de direita em posições de destaque nesta sub-rede reforça esta impressão.

Do lado das empresas, a análise revela que todas as ocupantes de posições centrais nas comunidades têm interesses vinculados à agenda supracitada, com diferentes níveis de proximidade em relação a ela. Na maioria, são os maiores grupos privados do país, com atuação em setores econômicos altamente afetados pelas políticas ambientais e de desenvolvimento que, no nível do legislativo federal, passam pela CMADS. Mesmo corporações do sistema financeiro, a princípio mais distantes da referida agenda, quando olhadas mais de perto, apresentam-se como organizações que encabeçam grupos de capital com vultosos investimentos em áreas como mineração, construção civil, sistemas agroalimentares e assim por diante.

Do lado dos deputados federais, as posições centrais das comunidades raramente são ocupadas por defensores de uma agenda de defesa do meio ambiente e do desenvolvimento sustentável e, em consequência, de políticas que vão nessas direções. Em contraste, amiúde serão encontrados conhecidos membros da bancada ruralista, para os quais as políticas públicas ambientais são objeto de interesse direto, bem como de seus grandes financiadores. Em suma, as comunidades do componente gigante da rede CMADS caracterizam-se pela homogeneidade,

\footnotetext{
12 Para classificação ideológica dos partidos brasileiros, consultar Zucco Jr. (2011), Tarouco e Madeira (2013) e Scheeffer (2018).
} 
sendo, em larga medida, praticamente indiferenciadas entre si.

O passo seguinte foi construir redes uni-modais de deputados e empresas, conforme procedimento descrito na seção anterior, que efetua a conexão direta entre nós de determinado tipo, pela supressão dos nós do outro tipo. Com isso, identificamos grupos de parlamentares aproximados por empresas e vice-versa, de modo a verificar se a referida homogeneidade se mantém ou se esses grupos são heterogêneos e forjados a partir de características singulares, especialmente, para os propósitos do estudo, de grupos de interesse específicos. Aqui também aplicamos dois filtros: mantemos apenas os nós do componente gigante com grau $\geq 2$.

Começando pela rede uni-modal dos parlamentares, a aplicação do algoritmo de modularidade (resolução 1.0) resultou em três comunidades, que podem ser visualizadas na Figura 5. Nos três grupos, há deputados dos mais diferentes partidos, representando diversas posições de um espectro ideológico que vai de centro-esquerda até a direita. Mercê da própria composição da CMADS na legislatura pesquisada, aqui mais uma vez se repete o padrão, de parlamentares mais identificados com a defesa das pautas ambientais aparecendo em menor número e nas posições mais periféricas. As posições mais centrais - que no layout escolhido estão nas extremidades dos eixos - são quase sempre ocupadas por defensores de agendas empresariais 
no tocante aos temas debatidos na comissão.

Figura 5 - Grafo da rede uni-modal de deputados federais distribuída por modularidade

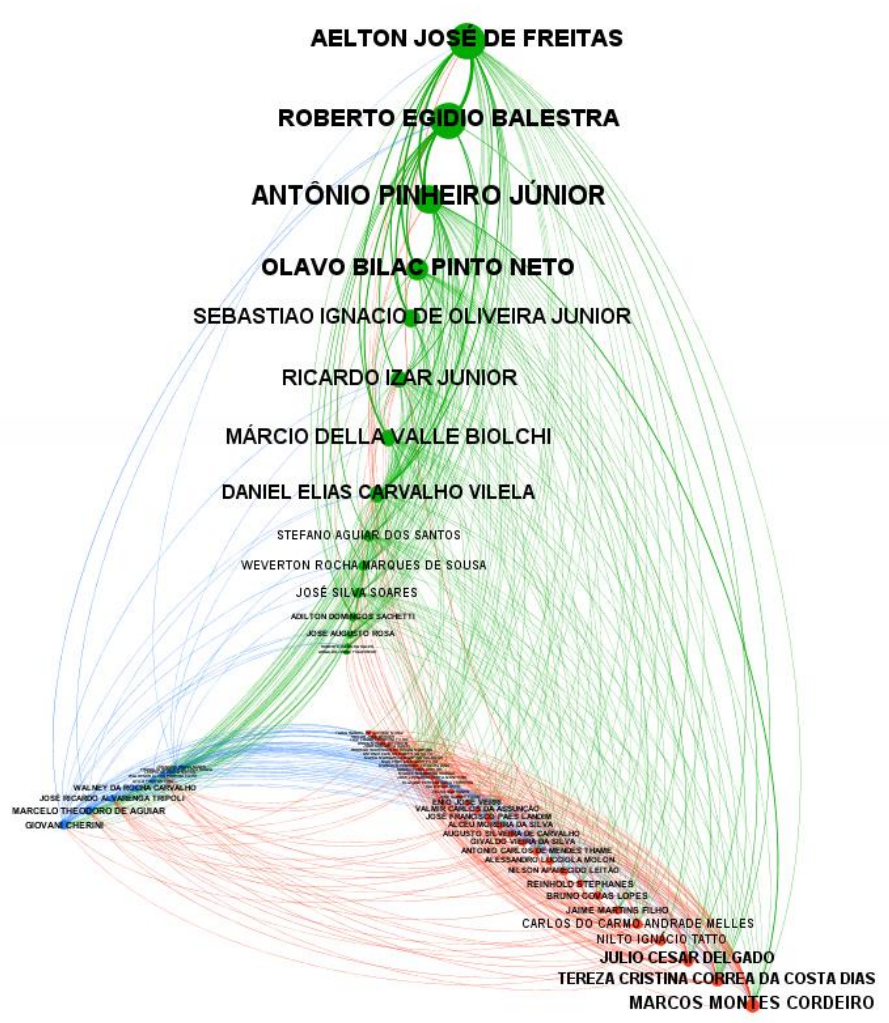

Fonte: Elaboração própria, com dados do TSE (BRASIL, 2019a) e da Câmara dos Deputados (BRASIL, 2015a, 2016, 2017, 2018).

A rede uni-modal das empresas, obtida pela ligação direta entre estas pela supressão dos nós dos deputados federais que elas financiam mutuamente, evidencia os metarrelacionamentos entre as corporações que financiaram os integrantes da CMADS na $55^{\circ}$ legislatura. A Figura 6 mostra o grafo desta rede. Aqui também fica clara a tendência das comunidades, vale dizer, as empresas que se aproximam por meio dos candidatos que apoiam, em se assemelhar bastante. Em regra, a composição das empresas por atividades econômicas se repetem nas comunidades - com destaque para os setores financeiro, de construção civil, extração mineral, metalurgia e siderurgia, 
além, é claro, da produção e industrialização de alimentos.

Figura 6 - Grafo da rede uni-modal de empresas distribuída por modularidade

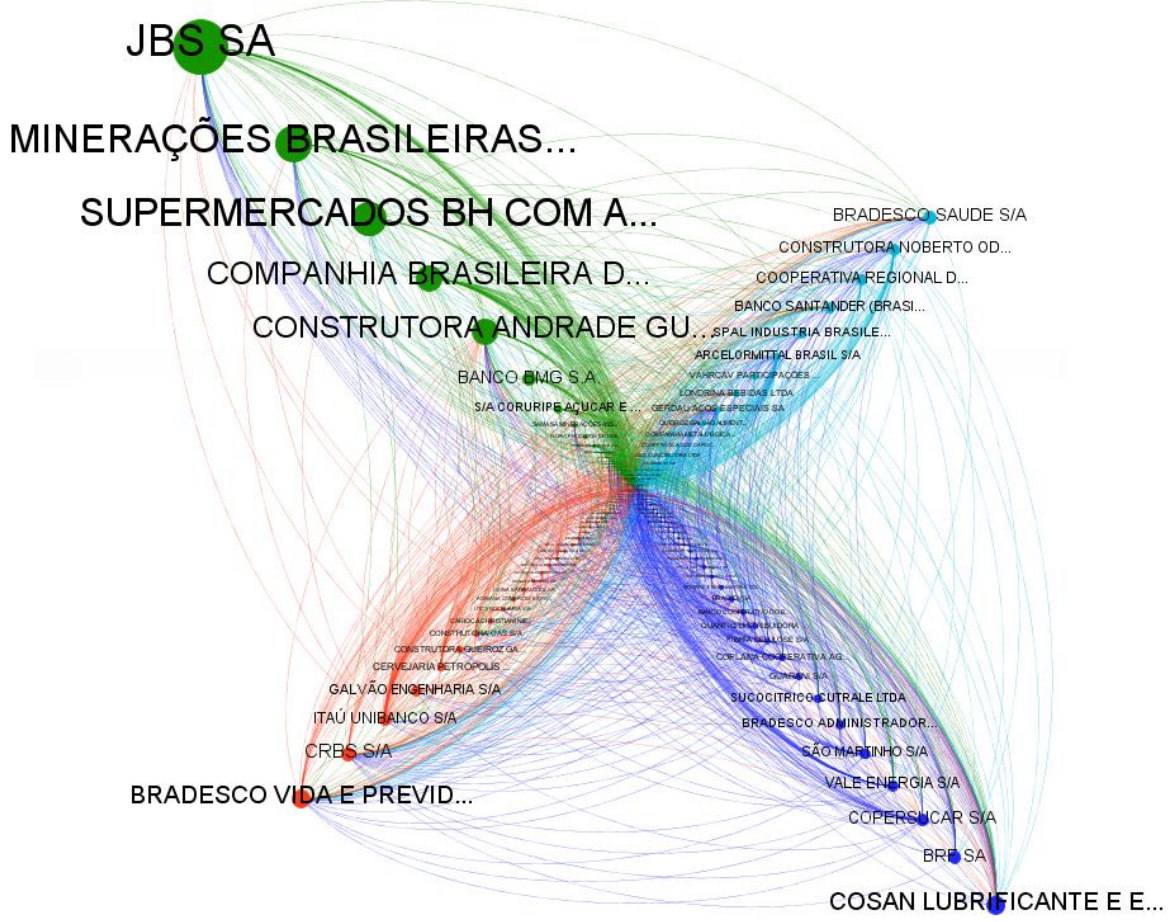

Fonte: Elaboração própria, com dados do TSE (BRASIL, 2019a) e da Câmara dos Deputados (BRASIL, 2015a, 2016, 2017, 2018).

Ambas as redes uni-modais confirmam, portanto, a homogeneidade na composição tanto das bancadas, quanto dos grupos de capital no núcleo mais central da rede de financiamento que, ao fim e ao cabo, elegeu os integrantes da CMADS. Esta topologia sinaliza para alguns comportamentos estratégicos por parte das empresas que financiam as campanhas dos deputados da comissão, especialmente aquelas que ocupam as posições privilegiadas na teia relacional da rede. O mais evidente é o de "distribuir ovos em várias cestas", ao financiar vários candidatos competitivos, de partidos os mais diversos, com diferentes orientações doutrinárias. O capital aqui tem poucos preconceitos ideológicos e pode-se inferir que ele busca assegurar-se da presença de quem o represente no legislativo, lócus privilegiado de produção de políticas públicas, em geral, e das políticas ambientais, para o caso específico. Como resultado, empresas de setores econômicos igualmente distintos, ainda que sempre com interesses afetados pelas pautas da CMADS, distribuem doações para os mesmos políticos, de modo que há um nítido 
entrecruzamento de interesses.

\section{Conclusão}

As redes de financiamento eleitoral apresentadas e analisadas na seção anterior permitem responder às perguntas que orientaram a pesquisa relatada neste artigo. Comecemos com a primeira: como é a estrutura da rede de financiamento dos membros da CMADS? Confirmando uma característica estrutural das redes complexas, a Rede CMADS possui uma topologia nitidamente assimétrica. Poucos atores - sejam empresas, sejam deputados federais - ocupam as posições centrais da rede, enquanto a grande maioria encontra-se na periferia. Este achado, por si só importante, ganha maior vulto quando se considera que a rede investigada é formada por deputados federais eleitos, ou seja, um grupo que já passou por um filtro que excluiu a grande massa de candidatos subfinanciados e com chances próximas de zero de se eleger.

Em outros termos, mesmo entre parlamentares eleitos, selecionados a partir de um determinado recorte temático - pertença à Comissão de Meio Ambiente e Desenvolvimento Sustentável, na $55^{\mathrm{a}}$ legislatura -, as hierarquias se colocam de maneira cristalina, com alguns deputados federais e algumas empresas desempenhando um papel de destaque em função da centralidade que exercem na rede.

A topologia também responde à segunda questão da pesquisa: quais grupos de capital político-econômico se formam e se conectam dentro da rede CMADS? Como se pode observar nos grafos apresentados, todas as comunidades de atores mais próximos se assemelham.

Do ponto de vista das empresas, quase que invariavelmente se sobressaem os maiores conglomerados privados do Brasil, representando setores com interesses mais ou menos diretos nas pautas que compõem a agenda da comissão, compostas por políticas públicas ambientais e de desenvolvimento. Entre os referidos setores, destacam-se atividades como construção civil, finanças, mineração e produção e processamento de alimentos. Do ponto de vista dos parlamentares que compõem as comunidades detectadas na rede, praticamente não há nomes mais identificados com a defesa de visões mais progressistas em relação à questão ambiental, o desenvolvimento e à própria sustentabilidade entre os atores centrais. Em vez disso, abundam políticos ligados à defesa de pautas conservadores e do agronegócio, por exemplo.

A conformação da rede - incluindo suas derivadas uni-modais - com empresas e deputados com as características acima suscita a hipótese de que os grupos de capital políticofinanceiro que a formam estão comprometidos com um determinado modelo de desenvolvimento, sinônimo de crescimento econômico, com a sustentabilidade (ambiental, social e econômica) em segundo plano. Trata-se de uma agenda que mantém sua força no Brasil, país que não logrou sair da semiperiferia do capitalismo.

Uma das possíveis estratégias para testar a hipótese gerada a partir dos resultados desta 
pesquisa é uma análise densa da atuação dos deputados federais que identificamos nas redes de financiamento vis-à-vis os interesses de seus financiadores e as diferentes vertentes que se constituem tem torno das questões ambientais e do desenvolvimento.

\section{Referências}

ALIER, J. M. Correntes do ecologismo. São Paulo: Contexto, 2007.

ARAÚJO, G. B. O déficit entre acordado e realizado no Mercosul. 2008. Dissertação (Mestrado em Ciência Política) - Faculdade Filosofia, Letras e Ciências Humanas, Universidade de São Paulo, São Paulo, 2008.

BACHRACH, P.; BARATZ, M. S. Two faces of power. American political science review, Cambridge, UK, v. 56, n. 4, p. 947-952, 1962. Disponível em: https://doi.org/10.2307/1952796. Acesso em: 15 jan. 2019.

MELLO, R. B. de; MARCON, R.; ALBERTON, A. Drivers of Discretionary Firm Donations in Brazil. Brazilian Administration Review, Maringá, v. 5, p. 4, p. 275-288, 2008. Disponível em: http://www.scielo.br/scielo.php?script=sci_abstract\&pid=S1807$76922008000400003 \& \operatorname{lng}=$ pt\&nrm=iso\&tlng=en. Acesso em: 15 jan. 2019.

BLONDEL, V. D. et al. Fast unfolding of communities in large networks. Journal of Statistical Mechanics: Theory and Experiment, n. 10, 2008. Dispon'vel em: https://iopscience.iop.org/article/10.1088/1742-5468/2008/10/P10008/meta. Acesso em: 15 jan. 2019.

BOAS, T.C.; HIDALGO, F.D.; RICHARDSON, N.P. The Spoils of Victory: Campaign Donations and Government Contracts in Brazil. The Journal of Politics, v. 76, n. 2, p. 415-429, 2014. Disponível em: http://www.mit.edu/ dhidalgo/papers/political_investment_2014.pdf. Acesso em: 15 jan. 2019.

BOURDOUKAN, A. Y. O bolso e a urna: financiamento político em perspectiva comparada. 2009. Tese (Doutorado em Ciência Política) - Faculdade Filosofia, Letras e Ciências Humanas, Universidade de São Paulo, São Paulo, 2009. Disponível em: https://www.teses.usp.br/teses/disponiveis/8/8131/tde-23112009102329/publico/ADLA_YOUSSEF_BOURDOUKAN.pdf. Acesso em: 15 jan. 2019.

BRASIL. Tribunal Superior Eleitoral. Repositório de dados Eleitorais. Brasília: TSE Disponível em: http://www.tse.jus.br/eleicoes/estatisticas/repositorio-de-dados-eleitorais. Acesso em: 15 jan. 2019(a).

BRASIL. Câmara dos Deputados. Relatório de atividades da Comissão de Meio Ambiente e Desenvolvimento Sustentável: gestão 2015. Brasília: CMADS, 2015a. Disponível em: http://www2.camara.leg.br/atividade-legislativa/comissoes/comissoespermanentes/cmads/documentos-1/relatorio-anual-de-atividades. Acesos em: 15 jan. 2019.

BRASIL. Câmara dos Deputados. Comissão de Meio Ambiente e Desenvolvimento Sustentável - Relatório de atividades: gestão 2016. Brasília: CMADS, 2016. Disponível em: http://www2.camara.leg.br/atividade-legislativa/comissoes/comissoespermanentes/cmads/documentos-1/relatorio-anual-de-atividades. Acesos em: 15 jan. 2019.

BRASIL. Câmara dos Deputados. Relatório anual de produtividade legislativa: gestão 2017. Brasília: CMADS, 2017. Disponível em: http://www2.camara.leg.br/atividade- 
legislativa/comissoes/comissoes-permanentes/cmads/documentos-1/relatorio-anual-deatividades. Acesos em: 15 jan. 2019.

BRASIL. Câmara dos Deputados. Relatório anual de produtividade legislativa: gestão 2018 . Brasília: CMADS, 2018. Disponível em: http://www2.camara.leg.br/atividadelegislativa/comissoes/comissoes-permanentes/cmads/documentos-1/relatorio-anual-deatividades. Acesos em: 15 jan. 2019.

BRASIL. Lei $\mathbf{n}^{\mathbf{0}} \mathbf{1 3 . 1 6 5}$, de 29 de setembro de 2015. Altera as Leis $\mathrm{n}^{\circ} 9.504$, de 30 de setembro de 1997, 9.096, de 19 de setembro de 1995, e 4.737, de 15 de julho de 1965 - Código Eleitoral, para reduzir os custos das campanhas eleitorais, simplificar a administração dos Partidos Políticos e incentivar a participação feminina. Brasília, DF: Presidência da República, 2015b. Disponível em: http://www.planalto.gov.br/ccivil_03/_ato20152018/2015/lei/113165.htm. Acesso em: 15 jan. 2019.

CAVALCANTI, C. Sustentabilidade: mantra ou escolha moral? Uma abordagem ecológicoeconômica. Estudos Avançados, São Paulo, v. 26, n 74, p. 35-50, 2012.

CERVI, E. U. Financiamento de campanhas e desempenho eleitoral no Brasil: análise das contribuições de pessoas físicas, jurídicas e partidos políticos às eleições de 2008 nas capitais de Estado. Revista Brasileira de Ciência Política, Brasília, v. 4. p. 135-167, 2010.

CERVI, E. U.; HOROCHOVSKI, R. R.; JUNCKES, I. J. Redes de doadores e financiamento político em 2014: distinguindo doações para candidatos, partidos e comitês financeiros nas eleições presidenciais brasileiras. E-Legis, Brasília, v.8, n.18, p. 80-100, 2015.

DAHL, R. A. Who governs? Power and democracy in an American city. New Haven: Yale University Press, 1961.

DALY, H. Crescimento sustentável? Não obrigado. Revista Ambiente e Sociedade, v. 7, n. 2, jul./dez. 2004.

DEGENNE, A.; FORSE, M. Introducing social networks. London: Sage, 2007.

FALGUERA, E.; JONES, S.; OHMAN, M. Funding of political parties and election campaigns: a handbook on political finance. Stockholm: IDEA, 2014.

FIGUEIREDO FILHO, D. B. O elo corporativo? Grupos de interesse, financiamento de campanha e regulação eleitoral. 2009. Dissertação (Mestrado em Ciência Política) - Centro de Filosofia e Ciências Humanas, Universidade Federal de Pernambuco, Recife, 2009. Disponível em: https://repositorio.ufpe.br/handle/123456789/1301. Acesso em: 15 jan. 2019.

FREEMAN, L. C. Centrality in social networks. Social Networks, v. 1, n. 2, p. 215-239, 1979. Disponível em: http://www.leonidzhukov.net/hse/2018/sna/papers/freeman79-centrality.pdf. Acesso em: 15 jan. 2019.

FURTADO, C. Essencial Celso Furtado. São Paulo: Editora Companhia das Letras, 2013. Disponível em: https://www.companhiadasletras.com.br/trechos/85097.pdf. Acesso em: 15 jan. 2019.

FURTADO, C. Criatividade e dependência na civilização industrial. São Paulo: Círculo do Livro, 1978.

GAVENTA, J. Power and powerlessness: Quiescence and rebellion in an Appalachian valley. Champaign: University of Illinois Press, 1982. 
GEARA, L. E. et al. O financiamento eleitoral nas comissões permanentes da Câmara Dos Deputados: uma análise do meta relacionamento entre empresas e parlamentares. E-Legis, Brasília, v. 11, n. 26, p. 60-81, ago. 2018. Disponível em: http://elegis.camara.leg.br/cefor/index.php/e-legis/article/view/409. Aceso em: 15 jan. 2019.

GEORGESCU-ROEGEN, N. O decrescimento: entropia, ecologia, economia. São Paulo: Senac, 2012.

HIGGINS, S. S.; RIBEIRO, A. C. A. Análise de redes em Ciências Sociais. Brasília: Escola Nacional de Administração Pública (Enap), 2018.

HOPWOOD, B. et al. Sustainable development: mapping different approaches. Sustainable Development, v. 13, n. 1, p.38-52, 2005. Disponível em:

https://onlinelibrary.wiley.com/doi/epdf/10.1002/sd.244. Acesso em: 15 jan. 2019.

HOROCHOVSKI, R. R. et al. As mudanças no Código Florestal Brasileiro: uma análise de gênero, ideologia partidária e financiamento de campanha das bancadas parlamentares. Guaju Revista Brasileira de Desenvolvimento Territorial Sustentável, Curitiba, v. 2, n. 2, p. 3-25, dez. 2016b.

HOROCHOVSKI, R. R. et al. Estruturas de poder nas redes de financiamento político nas eleições de 2010 no Brasil. Opinião Pública, São Paulo, v. 22, n. 1, p. 28-54, abr. 2016c.

HOROCHOVSKI, R. R. et al. Um modelo para capturar a relação entre financiamento eleitoral e contratação de bens e serviços: o caso de Curitiba. Newsletter - Observatório de Elites Políticas e Sociais do Brasil, Curitiba, v. 3, n.3, p. 1- 18, 2016 a.

HOROCHOVSKI, R. R. et al. Redes de financiamento eleitoral e grupos de capital na Comissão de Meio Ambiente e Desenvolvimento Sustentável da Câmara dos Deputados. Redes - Revista do Desenvolvimento Regional, Santa Cruz do Sul, v. 22, n. 3, p. 145-169, 2017.

IUCN, UNEP. WWF. World Conservation Strategy. Living Resource Conservation for Sustainable Development. Gland, Switzerland, IUCN, UNEP, WWF, 1980.

JACOBSON, Gary C. The effects of campaign spending in congressional elections. American Political Science Review, v. 72, n. 2, p. 469-491, 1978.

JUNCKES, I. J. et al.. Poder e democracia: uma análise da rede de financiamento eleitoral em 2014 no Brasil. Revista Brasileira de Ciências Sociais, São Paulo, v. 34, n. 100, e3410006, 2019.

LAVALLE, A G.; CASTELLO, G.; BICHIR, R. M. Protagonistas na sociedade civil: redes e centralidades de organizações civis em São Paulo. Dados, Rio de Janeiro, v. 50, n. 3, p. 465498, 2007.

LEMIEUX, V.; OUIMET, M. Análise Estrutural de Redes Sociais. Lisboa: Instituto Piaget, 2014.

LEMOS, L. B.; MARCELINO, D.; PEDERIVA, J. H. Porque dinheiro importa: a dinâmica das contribuições eleitorais para o Congresso Nacional em 2002 e 2006. Opinião Pública, São Paulo, v. 16, n. 2, p. 366-393, 2010.

LUKES, S. Power: A radical approach. London, Macmilllan, 1974.

MANCUSO, W. P. et al. Corporate Dependence in Brazil's 2010 Elections for Federal Deputy. Brazilian Political Science Review, São Paulo, v. 10, n. 3, p. 1-24, 2016. 
MANCUSO, W. P. Investimento eleitoral no Brasil: balanço da literatura (2001-2012) e agenda de pesquisa. Revista de Sociolo gia e Política, Curitiba, v. 23, n. 54, p. 155-183, 2015.

MANCUSO, W. P.; SPECK, B. W. Financiamento empresarial e desempenho eleitoral no Brasil: um estudo das eleições para deputado federal em 2010. In: WORKSHOP EMPRESA, EMPRESÁRIOS E SOCIEDADE, 8. 2012, Curitiba. Anais [...]. Curitiba: UFPR, 2012, p. 1-23.

MANCUSO, W. P.; HOROCHOVSKI, R. R.; CAMARGO, N. F. Financiamento eleitoral empresarial direto e indireto nas eleições nacionais de 2014. Revista Brasileira de Ciência Política, n. 27, p. 936, 2018.

MARQUES, E. C. Redes sociais e instituições na construção do Estado e da sua permeabilidade. Revista Brasileira de Ciências Sociais, São Paulo, v. 14, n. 41, p. 45-67, out. 1999.

MILGRAM, S. The small-world problem. PsychologyToday, v.1, n.1, p. 61-67, May 1967.

MILLS, C. W. The power elite. Oxford University Press, 1981.

MINELLA, A. C. Análise de redes sociais, classes sociais e marxismo. Revista Brasileira de Ciências Sociais, São Paulo, v. 28, n. 83, p. 185-194, 2013.

MIZRUCHI, M. S. Análise de redes sociais: avanços recentes e controvérsias atuais. Revista de Administração de Empresas, São Paulo, v. 46, n. 3, p. 72-86, abr. 2006.

MORENO, J. L. Sociometry in action. Sociometry, v. 5, n. 3, p. 298-315, 1942.

NEWMAN, M. Networks: an introduction. Oxford: Oxford University Press, 2010.

PAZ, F. H. S. Redes de parlamentares na Câmara dos Deputados: uma metodologia de análise da atuação política no Brasil. 2015. Dissertação (Mestrado em Desenvolvimento Territorial Sustentável) - Universidade Federal do Paraná - Setor Litoral, Mantinhos, 2015. Disponível em: https://acervodigital.ufpr.br/handle/1884/45111. Acesso em: 15 jan. 2019.

PEIXOTO, V. M. Eleições e financiamento de campanhas no Brasil. Rio de Janeiro: Garamond, 2016. 192 p.

PERISSINOTTO, R. M. et al . Redes sociais e recrutamento: o caso dos diretores e presidentes do Banco Central do Brasil (1994-2016). Tempo social, São Paulo, v. 29, n. 3, p. 61-82, dez. 2017.

PRZEWORSKI, A. Democracy, redistribution, and Equality. Brazilian Political Science Review, São Paulo, v. 6, n. 1, p. 11-36, 2012.

ROCHA, D. Relações entre dispêndios do BNDES e financiamento eleitoral no governo Lula: uma análise empírica. In: ENCONTRO ANUAL DA ASSOCIAÇÃO NACIONAL DE PÓSGRADUAÇÃO E PESQUISA EM CIÊNCIAS SOCIAIS - ANPOCS, 35. 2011, Caxambu. Anais [...]. São Paulo: ANPOCS, 2011. p. 1-15. Disponível em: http://anpocs.org/index.php/papers-35-encontro/gt-29/gt13-16/973-relacao-entre-emprestimosdo-bndes-e-financiamento-eleitoral-no-brasil/file. Acesso em: 15 jan. 2019.

SACCHET, T.; SPECK, B.W. Partidos políticos e (sub)representação feminina nas esferas legislativas: um estudo sobre recrutamento eleitoral e financiamento de campanhas. In: CONFERÊNCIA IPSA-ECPR “WHATEVER HAPPENED TO NORTHSOUTH?” 2011, São Paulo. Anais [...]. São Paulo: USP, 2011. 
SACHS, I. Caminhos para o Desenvolvimento Sustentável. Rio de Janeiro: Garamond, 2000a.

SACHS, W. Dicionário do desenvolvimento: guia para o conhecimento como poder. Petrópolis: Vozes, $2000 \mathrm{~b}$.

SAMUELS, D. Money, elections, and democracy in Brasil. Latin American Politics and Society, New York, v. 43, n. 2, p. 27-48, 2001.

SAMUELS, D. Pork Barreling is not Credit Claiming or Advertising: Campaign Finance and the Source of the Personal Vote in Brazil. The Journal of Politics, Chicago, v. 64, n. 3, p. 845$863,2002$.

SANTOS, M. L. O parlamento sob influência: o lobby da indústria na Câmara dos Deputados. 2011. Tese (Doutorado em Ciência Política) - Centro de Filosofia e Ciências Humanas, Universidade Federal de Pernambuco, Recife, 2011. Disponível em: https://repositorio.ufpe.br/handle/123456789/1484. Acesso em: 15 jan. 2019.

SANTOS, R.D. A economia política das eleições 2002: Um estudo sobre a concentração de financiamento de campanha para deputado federal. 2009. Dissertação (Mestrado em Ciência Política) - Departamento de Ciência Política, Universidade Federal Fluminense, Niterói, 2009. Disponível em: https://app.uff.br/riuff/bitstream/1/8266/1/Disserta\%C3\%A7\%C3\%A3o\%20de\%202009\%20Ro drigo\%20Dolandeli\%20dos\%20Santos.pdf. Acesso em: 15 jan. 2019.

SCHATTSCHNEIDER, E. E. The semi-sovereign people: A realist's view of democracy in America. Belmont, CA: Wadsworth Thomson Learning, 1988.

SCHEEFFER, F. A alocação dos partidos no espectro ideológico a partir da atuação parlamentar. E-Legis, Brasília, v. 11, n. 27, set./dez. 2018. Disponível em: http://elegis.camara.leg.br/cefor/index.php/e-legis/article/view/435. Acesso em: 15 jan. 2019.

TAROUCO, G. S.; MADEIRA, R. M. Partidos, programas e o debate sobre esquerda e direita no Brasil. Revista de Sociologia e Política, Curitiba, v. 21, n. 45, 2013.

THOMAS, V. et al. A qualidade do crescimento. São Paulo: Unesp, 2002.

WELCH, W. P. Money and votes: A simultaneous equation model. Public Choice, v. 36, n. 2, p. 209-234, 1981.

WHITE, H. C. Identity and Control: A Structural Theory of Social Action. Princeton: Princeton University Press, 1992.

WOLF, F. O comportamento dos deputados na Câmara Federal: uma abordagem de redes sociais. 2008. Dissertação (Mestrado em Ciência Política) - Instituto de Ciência Política, Universidade de Brasília, Brasília, 2008. Disponível em:

http://repositorio.unb.br/bitstream/10482/1165/1/DISSERTACAO_2008_FelipeWolf.pdf. Acesso em: 15 jan. 2019.

ZOVATTO, D. Financiamento dos partidos e campanhas eleitorais na América Latina: uma análise comparada. Opinião Pública, São Paulo, v. 11, n. 2, p. 287-336, 2005.

ZUCCO JR, C. Esquerda, direita e governo: a ideologia dos partidos políticos brasileiros. In: ZUCCO JR, Cesar; POWER, Timothy Joseph. O Congresso por ele mesmo: autopercepções da classe política brasileira. Belo Horizonte: Editora UFMG. 2011. p. 37-60. 
Artigo recebido em: 2019-06-10

Artigo reapresentado em: 2019-08-07

Artigo aceito para publicação em: 2019-10-07 